The International Journal of Indian Psychology: Volume: 01 | Issue: 04 No. 2 | ISSN 2348-5396

\title{
A Study of Anxiety among Male and Female Adolescents
}

\author{
A. K. Chaudhary*, Deepika Jain**
}

\begin{abstract}
ABATRACT
The purpose of the present study was to find out the level of Anxiety among male and female adolescents. The local of the study was confined of Udaipur city of Rajasthan. The sample consisted of 60 subjects divided into two groups, 30 Male and 30 Female adolescents. Test anxiety scale by Dr. V. P Sharma (1971) was used to collect data. Mean, S.D and ' $t$ ' test was calculated to analyze the data. Result showed that male adolescents have higher anxiety in comparison to female adolescents.
\end{abstract}

\section{INTRODUCTION}

Adolescence is the stage of development that lead a person from childhood to adulthood, marked by the major physical changes of puberty and important cognitive and social developments, it is generally considered to begin around age twelve and end sometime around age twenty.

Adolescence represents a second birth, in which evolutionary instinct was replaced by more civilized social and cultural influences, guided by parents and other adults who help transform the impulsive child into an altruistic, self-sacrificing, and moral human being. Hall's theory is mainly of historical interest; there is virtually no scientific support for his 'recapitulation' theory or for his view that adolescence is universally a time of "storm and Anxiety".

The adolescent years present new and unique challenges for children. They must come to terms with their bodylines as they suddenly grow taller and become sexually mature. They must establish more equal relationships with their parents and they must come to grips with the need to leave home eventually and become independent individuals. How stressful these challenges prove depends on a variety of circumstances.

\footnotetext{
* Senior Lecturer, Department of Psychology, Govt. M.G. College, Udaipur (Raj.) INDIA

** Research Scholar Dept. of Psychology, Mewar University, Chittorgarh (Raj.) INDIA
} 
For some teens, the timing of Puberty can make these years especially hard or easy. For others, their newly forming ability to reason abstractly can make life seem suddenly confusing at the same time that it reveals exciting new possibilities for the future.

For most young people, dating, or even just talking to the opposite sex proves both intriguing and frustrating as they slowly overcome childhood habits of relating only to members of their own sex. All in all, the changes of adolescences can be difficult, but on an average they are neither more nor less challenging than those children face during other span of life.

Young People become stressed for many reasons. The primary Sources of tension and trouble for teen and their friends were: relationship with friends and family; the pressure of expectation from self and others; pressure at school from teachers, coaches, grades and homework; financial pressures; and tragedy in the lives of family and friends.

Adolescences are a transition phase through which a child becomes an adult. It is a time of pubertal change, identity formation, social development and the acquisition of experiences and credentials promoting entry to adult's roles. Adolescences and early childhood are also critical period for the development of psychological attributes, such as political attitudes and work orientations that tend to persists through adulthood. Although it is a recognized stage in most part of the world, adolescence involves different experience for youth depending upon where they live. In western countries the adolescent is trough to be relatively free of adult responsibilities; lacking in long term commitments; oriented to fun, sports, popular music and peers; receptive to change; and ready to experiment with alternative identities.

Adolescence as a psychological concept was popularized by psychologist G Stanley Hall. He believed that such stage of child's physical and biological growth and personality development "recapitulated", or repeated, the same stage of development the occurred in the evolution of the human species. According to Hall, the selfish, self-centered, and aggressive behaviors of childhood reflect the more primitive stages of human history.

Anxiety is characterized by feeling of tension, frustration, worry, sadness, and withdrawal that commonly last form a few hours to few days whereas depression is both more severe and longer lasting.

According to the DSM-IV-TR, anxiety disorders can be broken down into the following type panic disorder,agrophiobia, specific phobia, social phobia, obsessive compulsive disorder, posttraumatic stress disorder, acute distress disorder, generalized anxiety disorder, anxiety
(C) 2014 www.ijip.in
July-September 2014
72 | P a g e 
The International Journal of Indian Psychology: Volume: 01 | Issue: 04 No. 2 | ISSN 2348-5396

disorder due to a general medical condition, substance-induced anxiety, and anxiety disorder not otherwise specified (American Psychological Association, 2000, p.429).

Mental anxiety and depression were recognized as an illness caused bydemonic influence, but they were seen as curable. Treatments at this time included exorcism, bloodletting and some more humane treatments like ointments or baths (Barlow \& Durand, 2005).

Accounting to Beverly (2010), stress is the body's adaptation response to any demand or Pressure. These demands or pressure are called stressors. Teens are not immune to anxiety; however, they are sometimes ill-equipped to cope with the stressors that they face leading to various manifestations of that stress in their daily lives.

According to Katrina (2009), "Many people believe that the anxiety experienced by upper secondary school girls relates only to school. However, the picture is far broader. Girls Feel responsibility for various types of relationships, such as with friends and siblings, or have Taken upon themselves leisure time commitments in various associations and organizations.

According to Kenneth Kender (2007) many teenagers are seriously affected with the experience of stress and depression. They may rely on their negative or positive behaviors while dealing with their problems Stress features feeling of anxiety, frustration, worry and withdrawal and a typical session of anxiety may last for few hours to few days.

Kathryn and others suggested that adolescents are exposed to increased rates of stressful life experiences and there is some evidence that increases in stressors account, at least in part for the increased rates of psychological problems associated with this developmental period.

\section{OBJECTIVE:}

- To study the level of anxiety among male adolescents.

- To study the level of anxiety among female adolescents.

- To compare the level of anxiety among male and female adolescents.

\section{HYPOTHESIS:}

There is no significant difference between anxiety of male and female adolescents. 
The International Journal of Indian Psychology: Volume: 01 | Issue: 04 No. 2 | ISSN 2348-5396

\section{MEHODOLOGY}

\section{Sample}

The sample was selected from Udaipur city of Rajasthan. It consisted of 30 male and 30 female adolescents.

\section{Tool}

Teat anxiety scale developed by Dr. V.P Sharma (1971) was used to measure test anxiety. The test measures anxiety of adolescents. The test consists of 48 items. The test is standardized and having reliability $=.75$ and validity $=.64$.

\section{Procedure}

The test was administered individually upon the male and female adolescents. Brief instructions were given to them. The answered questionnaires were collected scored according to the manual. The scores obtained were analyzed statistically. Measures of central tendency and variability were calculated. The ' $t$ ' test is applied to see the significant difference between anxiety of male and female adolescents.

\section{Analysis of Data}

Table 1 shows the anxiety of male and female adolescents.

Table 1

\begin{tabular}{|l|c|c|l|l|}
\hline Group & Mean Anxiety Scores & $\mathrm{N}$ & S.D. & Interpretation \\
\hline Male & 60.56 & 30 & 4.24 & High \\
\hline Female & 64.10 & 30 & 2.85 & Average \\
\hline
\end{tabular}


The International Journal of Indian Psychology: Volume: 01 | Issue: 04 No. 2 | ISSN 2348-5396

Table showing scores on Anxiety variable.

\begin{tabular}{|l|c|c|c|c|c|}
\hline Groups & N & Mean & S. D. & t value & Significance \\
\cline { 1 - 4 } Female & 30 & 60.56 & 4.24 & 3.79 & 0.01 \\
\cline { 1 - 4 } Male & 30 & 64.10 & 2.85 & & \\
\hline
\end{tabular}

*significant at 0.01 level

Result shows that level of anxiety in males is higher as compared to female adolescents. Over monitored life, submissiveness due to socialization pattern, their docility makes them Anxiety in comparison to female adolescents, feeling of competition in every work and Confusion in taking decisions, wasting the time and excess work to get target, less stamina, Lack of ability to do work etc makes male adolescents more anxious than female adolescents. This may be due to during the transmission to adulthood, lack of knowledge and awareness, physiological changes promote psycho-social anxiety.

\section{REFERENCES:}

\section{The International Journal of no}

1. Antognoli, T. and Paula, L. (2000). Parent-Child Relationship, Family Structure, and loneliness among Adolescents. Ph.D. Thesis, Texas Woman's University.

2. American Psychiatric Association. (2000). Diagnostic and statistical manual of mental disorders (4th ed.). Washington, DC: Author.

3. Beardslee, W.R. and Gladstone, T.R. (2005). Biological Psychiatry. 49:1101-1110

4. Beverly, P.(2010). Adolescence anxiety, Stressors and Coping.

5. Birmaher,B.; Ryan, N.D. and Williamson, D.E. Brent, D.A. Kaufman, J,; Dahl, R.E.; Perel, j. and Nelson, B. journal of the American Academy of child and adolescent Psychiatry (1996). 35:1427-1439.

6. Barlow, D. H., \& Durand, M.V. (2005). Abnormal psychology: An integrative approach (4th Ed.). London: Thomson-Wadsworth. 
The International Journal of Indian Psychology: Volume: 01 | Issue: 04 No. 2 | ISSN 2348-5396

7. Brimaher, B.; Ryan, N.D. and Williamson, D.E. et al. (1996). Childhood and adolescent depression: a review of the past 10 years. Part II. Journal of the American Academy of child and adolescent Psychiatry. 35(12): 1575-83

8. Brimaher B., Brent D, et al. (1998). Practice parameters for the assessment and treatment of children and adolescents with disorders. J Am Acad Child Adolescent Psychiatry.37:63s-82s.

9. Conger, R.D.; Patterson, G.R. and Ge.X. (1995). It takes two to replicate: A Meditational model for the impact of parent,s stress on adolescent adjustment. Child Development, $66,80-97$

10. Eaton, W.W. (2001). The sociology of mental disorders (3rded.). New york: Praeger.

11. Fred, K,; Berger(2001). Addiction and Forensic Psychiatrist, Scripps Memorial Hospital, LaJolla, California.

12. Ge X. and Conger, R.D., (2003). Pubertal transition, stressful life event, and the emergence of gender differences in adolescent depressive symptoms. Developmental Psychology, 37, 1-20.

13. Ge.X., Conger, R.D., Cadoret, R.J., Neiderhiser, J.M. (1996b). The developmental interface between nature and narture: A mutual influence model of child antisocial behavior and parent behaviors. Developmental Psychology, 32(4), 574-589.

14. Goodwin, R.D.; Ferguson, D.M. and Horwood L.J. (2003). Neuroticism in adolescence and psychotic symptoms in adulthood.

15. Jellinek, M.; Little, M.; Murphy, J.M. and pagano, M.(1995). The pediatric Symptom Checklist. Support for a role in a managed care environment. Arch Pediatric adolescent Mde; 149:740-6.

16. Jellinek, M.S. and Snyder, J.B. (1998). Depression and suicide in children and adolescents. Pediatric Rev. 19: 255-64.

17. Johnson G. David (1993), Adolescent Anxiety: Causes and Consequences. Journal of comparative family studies.

18. Joseph, J. (1994). The Resilient Child. New York: Plenum Press

19. Katarina Haraldson, (2009). How adolescent girls manage anxiety.University of Gothenburg.

20. Kender, K. (2007).Adolescent anxiety and Depression. 
The International Journal of Indian Psychology: Volume: 01 | Issue: 04 No. 2 | ISSN 2348-5396

21. Kovcs, M. Obrosky, D.S. and Gatsonis, C. et al. (1997). First-episode major depressive and dysthymic disorder in childhood: clinical and socio demographic factors in recovery. J Am Acad Child Adolescent Psychiatry. 36(6): 777-84.

22. Kovacs, M. (1996). Presentation and course of major depressive disorder during childhood and later years of the life span. J Am Acad Child Adolescent Psychiatry. 35 (6): 705-15.

23. Nolen, S. (1998). Reasons for studying: motivational orientation \& study Strategies, cognitive \& instrucation, $5,269-287$

24. Paul Ballas, D.O. Department of Psychiatry, Thomas Jefferson University Hospital, Philadelphia.

25. Radloff, L.S. (1991). The use of the centre for Epidemiological Studies Dpression Scale for research in adolescents and young adults, Journal of Youth and Adolescence, 20(2), 149-165.

26. Rao, U.; Ryan, N.D. and Birmaher B, et al. (1995). Unipolar depression in adolescents: Clinical outcome in adulthood. J Am Acad Child Adolescent Psychiatry; 34(5): 566-78.

27. Ustun, T.B. and Sartorius, N. (1995). Mental illness in General Care: An nternational study. John Wiley on behalf of the World Health Organization.

28. Walker J.(2005). Adolescent Stress And Depression.

29. Winter, R.F. (ed.) (1983). Coping with executive anxiety, New York: Mc Graw Hill

30. Wolfenshon, J. (1995). A new biennial report-working for women's Empowerment and Gender Equality. United Nations fund for Women (UNIFEM). 